\title{
A MORTE NA COSMOVISÃO WAPIXANA
}

Carlos Alberto M. Cirino ${ }^{1}$

RESUMO: O artigo fornece alguns dados sobre a cosmovisão Wapixana no que concerne a elaboração da idéia de morte, a partir de artigos publicados na década de 40.

Palavras - chave: Wapixana; cosmovisão; morte.

ABSTRACT: This article contains informations about the cosmovision of Wapixana indians in relation to the idea of death from articles published for fifty years ago.

Key words: Wapixana; cosmovision; death.

\footnotetext{
1. Professor Assistente da Universidade Federal de Roraima/UFRR e Doutorando em Ciências Sociais (Antropologia) pela Pontifícia Universidade Católica de São Paulo - PUC.

Bol. do Mus. Integrado de Roraima, Boa Vista, 4 (único):5-10, 1996
} 


\section{INTRODUÇÃO}

o objetivo deste trabalho é especificar alguns aspectos sugeridos no trabalho de Lucila HERRMANN, Gioconda MUSSOLINI e D. Mauro WIRTH ${ }^{2}$ sobre a cosmovisão dos Wapixana ${ }^{3}$, publicados na Revista de Sociologia de São Paulo na década de 40.

$\mathrm{Na}$ verdade, apenas uma pequena parte desta cosmovisão será aqui esboçada: a morte com relação ao mundo dos vivos no pensamento Wapixana. O resgate da cosmologia do grupo é fundamental no registro das mudanças que se processaram nos últimos anos, em decorrência dos contatos estabelecidos, principalmente da ação evangelizadora da Igreja Católica.

\section{A morte e algumas categorias no imaginário Wapixana}

Os Wapixana acreditavam numa antiga lenda referente ao período em que um grande herói, um líder e mesmo o criador do mundo chamado Tuminkar ou Tuminkáre (WIRTH, 1943; p. 258) teria chamado seu povo e ensinado como evitar os perigos, ou seja, como se livrar das doenças, como se livrar dos maus espíritos, ensinamentos que infelizmente, em alguns casos foram esquecidos, razão que explicaria os padecimentos e a impossibilidade de defesa contra certos males.

Nestes termos, a morte era apreendida como proveniente da atuação de maus espíritos que agiam por intermédio de um feiticeiro e a não perpetuação da vida era consequência, portanto, do esquecimento de tais ensinamentos.

2. Dr. Mauro WIRTH foi designado, enquanto missionário beneditino, a presidir a Prelazia do Rio Branco em 1934, ficando até o ano de 1939, período em que coletou vasto material sobre os Wapixana que mais tarde seria utilizado como material empírico de tese de Lucila HERRMANN da Escola Livre de Sociologia e Política de São Paulo e de um artigo de Gioconda MUSSOLINI. Os capítulos da tese de HERRMANN foram publicados separadamente na revista de Sociologia de São Paulo juntamente com o artigo de MUSSOLINI e do próprio WIRTH entre 1940 e 1945 .

3. Os Wapixana são um grupo de língua Aruak e considerada uma das maiores etnia indígena de Roraima, contando hoje com uma população aproximada de 500 índios do lado brasileiro e 700 localizados na República da Guiana. Os contatos mais sistemáticos com a sociedade nacional e os missionários datam do começo deste século.

Bol. do Mus. Integrado de Roraima, Boa Vista, 4 (único):5-10, 1998 
Os maus espíritos eram representados no imaginário dos Wapixana pelos "Kanaimés", entidades malignas enviadas pelos inimigos e que poderiam causar a morte e outros males físicos. Acreditavam que os kanaimés nunca atacavam mais de um indivíduo, para não serem vistos e não derramavam sangue de suas vítimas, quebrando-lhes apenas os ossos e introduzindo um veneno mágico no organismo. Também se reportavam a uma substância denominada na língua wapixana de "djokoro" que os faziam invisíveis. Era interessante observar que para os Wapixana, os kanaimé eram sempre o "outro" ou seja, os índios das etnias circunvizinhas. A esse respeito observa KochGrunberg:

"Kanaimé puede ser determinada persona. El vengador de una ofensa, ejecutor de la vinganza de un asesinato, que muchas veces persigue a su víctina durante anos hasta lograr su objetivo, el asesino clandestino que vaga especialmente de noche, algún hombre malo que perjudica a otros con sus hechicerías, todos ellos "hacen Kanaimá" que es como dice el indio. (...) Tribus enteras puedem ser Kanaimé. Tribus vecines hostiles, tribus cuya enemistad anterior se ha convertido en una amistad dudosa, son abierta o secretamente consideradas como Kanaimé. Siempre una tribu llama a otra de este modo." (KOCH-GRUNBERG， 1966; p. 186).

Entre os Wapixana, quando alguém estava para morrer, os parentes o retiravam de sua rede, estendendo-a no chão e sobre ela o agonizante. Parentes, vizinhos e o pajé permaneciam sempre ao seu lado. Logo após a morte era envolto na própria rede, não sendo mais permitido olhar para o seu rosto, por superstição e também por respeito. Nos primeiros instantes do falecimento havia lamentos, lágrimas e cantos que expressavam um sentimento de dor. Enterrados com o rosto para cima e para a nascente do sol, quando homem tinha sua flecha e arco quebrado sobre a sepultura. Uma antiga tradição Wapixana indicava que o defunto deveria ser enterrado num recinto da casa, sendo em seguida abandonada e queimada.

Segundo os dados coletados por WIRTH e analisados por MUSSOLINI (1944; p. 145), os Wapixana acreditavam que o indivíduo tinha duas almas e três espíritos. A alma verdadeira que residia no coração e com a morte iria para o criador

Bol. do Mus. Integrado de Roraima, Boa Vista, 4 (único):5-10, 1998 
(Tuminkar/Tominikáre). Uma segunda de menos importância, localizada na língua, sendo a fala creditada ao poder dessa alma. Quanto aos espíritos, o indivíduo teria aquele a quem chamava de a "minha sombra". Na verdade era a própria sombra que se projetava quando havia sol.

O segundo espírito, uma outra sombra, menos nítida e projetada por dois focos de luz. E finalmente o espírito do pulso, designado como uma espécie de coração do braço. Acreditavam, ainda, que as almas dos indivíduos se separavam do corpo o que poderia levá-los à morte, sempre em função da ação dos Kanaimés.

Os Wapixana tinham um grande temor pela morte, chegando a acreditar que os próprios mortos do grupo com quem teriam entrado em atrito em vida, poderiam se transformar numa espécie de Kanaimé, pelo simples fato de não mais pertencerem ao mundo dos vivos. Na verdade, eles não conseguiam separar o mundo dos mortos do mundo dos vivos, admitindo a possibilidade de uma intermediação entre os dois mundos. Nos rituais de cura - pajé conseguia ver seus parentes mortos e através deste contato descobrir os meios necessários para a cura.

o morto, também, poderia se tornar um intermediário, zelando pelos vivos e recomendando as suas boas qualidades quando da morte ao grande criador, Tuminkar/Tominikáre, segundo as anotações de WIRTH. Esta intermediação era responsável pelo respeito a certas normas de conduta social.

Segundo MUSSOLINI (1944), as indicações sobre o destino pós-morte na cosmovisão dos Wapixana feita por WIRTH não coincidem em alguns pontos com as informações coletadas sobre os Wapixana do lado guianense.

Foi Curtis FARABEE (1918) quem estudou os Wapixana da antiga Guiana Inglesa e de acordo com suas informações os mesmos acreditavam não haver outra vida depois da morte e nem recompensas ou punições por ações praticadas em vida. Já para WIRTH havia uma crença numa vida futura e numa vida errante para aqueles que cometeram faltas no mundo dos vivos.

MUSSOLINI (1944) considerando o fato de não ter elaborado um trabalho etnográfico, levanta a hipótese das contradições serem decorrentes da influência católica que já promovia modificações nas crenças do grupo.

Nas anotações das narrativas do ritual pré-mortuário, o que chamou a atenção foi a presença do padre, além do pajé,

Bol. do Museu Integrado de Roraima, Boa Vista, 4 (único):5-10, 1998 
este ultimo convocado apenas para tratar do doente, o primeiro para encomendar a alma, ou seja, ministrar a unção dos enfermos. O pajé já tinha perdido uma de suas atribuições, conclusão minha.

Nos relatos de WIRTH encontrava-se referência ao gradativo abandono da tradição de enterrar os mortos dentro de casa e falava da introdução do enterro em cemitérios. As observações de WIRTH sobre a cosmovisão dos Wapixana tem um caráter muito dicotômico, tão presente na doutrina cristã (salvação/perdição, céu/inferno), e entendo como uma camisa de força, procurando aproximar ou sincretizar expressões de religiosidades diferentes.

Vejamos um trecho do artigo de WIRTH (1943, p. 258) : "Não conhecemos lendas que se referem explicitamente a formação do mundo. Os Vapidiana contam, entretanto, que Tominikáre (que corresponde mais ou menos ao Deus dos cristãos), que criou o mundo, (...)." (o grifo é meu).

- que percebo através da leitura feita das anotações de WIRTH era o processo ideológico de minar por dentro uma cultura e posso concluir que o paradigma teológico da "inculturação" não é tão recente como se apresenta.

\section{BIBLIOGRAFIA}

FARABEE, Curtis. 1918. The arwaks of Northern Brazil and Southern Bristish Guiana. American Journal of Physical Antropology, Philadelphia, v. 1, n 4. p. 427-441.

HERRMANN, Lucila. 1947. A Organização Social dos Vapidiana do Território do Rio Branco. Revista de Sociologia, São Paulo, v. 8. p. 119-134, 203, 215, 282-304. São Paulo, v. 9, p. 5484.

KOCH-GRUNBERG, Theodor. 1966. Del Roraima al Orinoco, tomo III, Ediciones del Banco Central de Venezuela. Trad. "Vom Roraima zum Orinoco", Stuttgart, 1923.

4 Conceito propriamente teológico que entrou no vocabulário da evangelização a partir de 1977. Processo ativo de assimilação da mensagem evangélica a partir de dentro da cultura

Bol. do Mus. Integrado de Roraima, Boa Vista, 4 (único):5-10, 1998 
MUSSOLINI, Gioconda. 1944. Notas Sobre os Conceitos de Moléstia, Cura e Morte entre os Índios Vapidiana. Revista de Sociologia, São Paulo, V. VI, p.134-155.

WIRTH, Mauro. 1943. A Mitologia dos Vapidianos do Brasil. Revista de Sociologia, São Paulo, v. 5, n³, p. 257-268.

Recebido em: 15.05.97

Aceito em: 29.06.97

Bol. do Mus. Int. de Roraima, Boa Vista, 4 (único):5-10, 1998 